Applied Remote Sensing

\title{
Field demonstration of a $1 \times 4$ fiber sensor array for subsurface carbon dioxide monitoring for carbon sequestration
}

Benjamin Soukup

Kevin S. Repasky

John L. Carlsten

Geoff Wicks 


\title{
Field demonstration of a $1 \times 4$ fiber sensor array for subsurface carbon dioxide monitoring for carbon sequestration
}

\author{
Benjamin Soukup, ${ }^{\mathrm{a}}$ Kevin S. Repasky, ${ }^{\mathrm{a}}$ John L. Carlsten, ${ }^{\mathrm{b}}$ and \\ Geoff Wicks \\ ${ }^{a}$ Montana State University, Department of Electrical and Computer Engineering, Cobleigh Hall \\ Room 610, Bozeman, Montana 59717 \\ repasky@ece.montana.edu \\ ${ }^{\mathrm{b}}$ Montana State University, Department of Physics, EPS 264, Bozeman, Montana 59717
}

\begin{abstract}
A fiber sensor array for subsurface $\mathrm{CO}_{2}$ concentration measurements was developed for monitoring geologic carbon sequestration sites. The fiber sensor array uses a single temperature-tunable distributed feedback (DFB) laser operating with a nominal wavelength of $2.004 \mu \mathrm{m}$. Light from this DFB laser is directed to one of the four probes via an inline $1 \times 4$ fiber optic switch. Each of the four probes is buried and allows the subsurface $\mathrm{CO}_{2}$ to enter the probe through Millipore filters that allow the soil gas to enter the probe but keeps out the soil and water. Light from the DFB laser interacts with the $\mathrm{CO}_{2}$ before it is directed back through the inline fiber optic switch. The DFB laser is tuned across two $\mathrm{CO}_{2}$ absorption features, where a transmission measurement is made allowing the $\mathrm{CO}_{2}$ concentration to be retrieved. The fiber optic switch then directs the light to the next probe where this process is repeated, allowing subsurface $\mathrm{CO}_{2}$ concentration measurements at each of the probes to be made as a function of time. The fiber sensor array was deployed for 58 days beginning from June 19, 2012 at the Zero Emission Research Technology field site, where subsurface $\mathrm{CO}_{2}$ concentrations were monitored. Background measurements indicate that the fiber sensor array can monitor background levels as low as 1000 parts per million (ppm). A 34-day subsurface release of 0.15 tones $\mathrm{CO}_{2}$ /day began on July 10,2012 . The elevated subsurface $\mathrm{CO}_{2}$ concentration was easily detected by each of the four probes with values ranging over $60,000 \mathrm{ppm}$, a factor of greater than 6 higher than background measurements. (C) The Authors. Published by SPIE under a Creative Commons Attribution 3.0 Unported License. Distribution or reproduction of this work in whole or in part requires full attribution of the original publication, including its DOI. [DOI: 10.1117/1 .JRS.8.083699]
\end{abstract}

Keywords: carbon dioxide; fiber optic applications; absorption.

Paper 12398 received Nov. 1, 2012; revised manuscript received Nov. 21, 2013; accepted for publication Nov. 25, 2013; published online Jan. 2, 2014.

\section{Introduction}

The average atmospheric concentration of carbon dioxide $\left(\mathrm{CO}_{2}\right)$ has been monitored continuously beginning in Mauna Loa Observatory in Hawaii since 1957. ${ }^{1,2}$ The average atmospheric concentration of $\mathrm{CO}_{2}$ has risen over the past 55-year observation record from a mean value of 315.97 parts per million (ppm) in 1959 to $391.57 \mathrm{ppm}$ in 2011. Furthermore, the rate of change of the atmospheric concentration of $\mathrm{CO}_{2}$ has increased from an average value of $0.85 \mathrm{ppm} /$ year between 1960 and 1969 to $1.96 \mathrm{ppm} /$ year between 2000 and 2009. Records of $\mathrm{CO}_{2}$ concentrations from other sites around the globe show similar results. ${ }^{2}$

The increasing level of atmospheric $\mathrm{CO}_{2}$ is due to anthropogenic activity including the burning of fossil fuel and land-use changes. ${ }^{3-5}$ The $\mathrm{CO}_{2}$ emission from fossil fuel combustion was 7.9 gigatones of carbon $(\mathrm{GtC})$ per year in 2005, whereas the $\mathrm{CO}_{2}$ emission from land-use changes, mainly clearing of land, was $1.5 \mathrm{GtC}$ per year in $2005 .{ }^{6}$ Atmospheric $\mathrm{CO}_{2}$ is estimated to contribute approximately $63 \%$ of the gaseous radiative forcing responsible for anthropogenic climatic change. The increasing atmospheric concentration of $\mathrm{CO}_{2}$ resulting from anthropogenic 
sources including fossil fuel consumption and land-use changes is causing international concern regarding their effects on the climatic system. ${ }^{7-15}$

Carbon sequestration ${ }^{16-21}$ is one method for mitigating the emission of $\mathrm{CO}_{2}$ from power generation facilities. Carbon sequestration captures the $\mathrm{CO}_{2}$ at the source, such as coal-fired power plants, and then injects the $\mathrm{CO}_{2}$ into geologic formations to minimize the $\mathrm{CO}_{2}$ emissions into the atmosphere. Furthermore, injection of $\mathrm{CO}_{2}$ can be used for enhanced oil recovery (EOR) extending the production lifetime of oil wells. A variety of carbon sequestration projects on the commercial scale is under way including the Sleipner Saline Aquifer Storage Project, ${ }^{22}$ currently storing $\mathrm{CO}_{2}$ beneath the North Sea, and the Weyburn Project in Canada, ${ }^{23,24}$ which is using injected $\mathrm{CO}_{2}$ for EOR to extend the lifetime of the oil fields. Furthermore, in the United States, seven regional Carbon Sequestration Partnerships ${ }^{25}$ are working to develop the science and technology needed for successful and safe carbon sequestration and EOR.

Monitoring instrumentation is one of the many areas of technology development needed for successful carbon sequestration. ${ }^{26-33}$ This instrumentation will be needed for both down-well and near-surface measurements for tracking the fate of the $\mathrm{CO}_{2}$ once it is injected, and for ensuring both carbon sequestration site integrity and public safety. These needs will require monitoring technology based on seismic detectors and down-well sensors for both pressure and temperature. A variety of monitoring tools and techniques will need to be developed to encompass the wide variability in the carbon sequestration sites. One specific group of detection tools currently in development utilizes the light from a tunable distributed feedback (DFB) laser to monitor molecular absorption of ambient air, allowing $\mathrm{CO}_{2}$ concentrations to be found. ${ }^{34-38} \mathrm{In}$ this article, the development and demonstration of a $1 \times 4$ fiber sensor array operated with a DFB laser for subsurface monitoring of $\mathrm{CO}_{2}$ are presented.

The $1 \times 4$ fiber sensor array utilizes a single DFB laser operating in the continuous wave mode with a nominal operating wavelength near $2 \mu \mathrm{m}$ to make integrated path differential absorption (IPDA) measurements of subsurface $\mathrm{CO}_{2}$ concentration. The light from the DFB laser is directed by a $1 \times 4$ fiber optic switch to the first of four probes that are placed underground. The light interacts with the subsurface $\mathrm{CO}_{2}$ and is then directed back through the switch to a transmission detector. The DFB laser is scanned over $\mathrm{CO}_{2}$ absorption features, allowing subsurface $\mathrm{CO}_{2}$ concentrations to be retrieved. The fiber optic switch then addresses the second probe, and this process is repeated until measurements at all four probes have been completed, at which point the process is repeated.

The predecessor to this $1 \times 4$ array was tested in the years prior to the 2012 test of this instrument. This previous instrument did not incorporate a fiber switch and used only a single subsurface sensor. Four probes were chosen as a tractable means to test the scalability of the system as pertinent for use at commercial or large-scale sequestration sites.

This $1 \times 4$ sensor array offers a variety of advantages for commercial and scientific uses. The send/call geometry of the programming allows the fiber array to be scaled to $N$ probes in a costeffective manner by utilizing a single laser, two detectors, and one fiber optic switch, which are the expensive components, while designing the probes to be low cost. Commercial switches with up to $1 \times 50$ are available ${ }^{39}$ which allows this technology to scale up to a $1 \times 50$ array, leading to a low-cost sensor array since the cost of each fiber probe is minimal. Comparable point sensor arrays for $\mathrm{CO}_{2}$ can easily add an order of magnitude in terms of cost for a system of the same size. Furthermore, because the instrument utilizes all fiber optic components, the sensor can be easily configured for field deployment and is not affected by adverse weather conditions. The system is also designed to run completely autonomously for extended periods of time and only requires personnel for data retrieval. Finally, even operating with a very low-power DFB laser and short-length free-space cells, subsurface $\mathrm{CO}_{2}$ fluctuations due to microbial activity can be monitored. Integration of a second DFB laser and a multiplexer could allow for measurements of subsurface oxygen $\left(\mathrm{O}_{2}\right)$ levels and conclusions to be drawn on changes in soil gas content and its causes.

This article is organized as follows. A brief discussion of IPDA spectroscopy is presented in Sec. 2. In Sec. 3, a description of a $1 \times 4$ fiber sensor array is presented. Data from a 58-day field deployment at a controlled subsurface release of $\mathrm{CO}_{2}$ at the Zero Emission Research Technology (ZERT) field site ${ }^{40,41}$ are presented in Sec. 4. Finally, some brief concluding remarks are presented in Sec. 5. 


\section{Integrated Path Differential Absorption Spectroscopy}

The atmospheric concentration of a molecular species can be related to the transmission of light by considering the optical depth, $\alpha L$, where $\alpha$ is the absorption per unit length for the molecular species of interest and $L$ is the length of the light that interacts with the molecular species of interest. The optical depth can be related to the molecular line strength, $S$, and the normalized lineshape, $g\left(v-v_{0}\right)$, by the relationship ${ }^{26}$

$$
\alpha L=S g\left(v-v_{0}\right) N P_{a} L
$$

with $N=N_{L}\left(296 / T_{\alpha}\right)$ is the total number of molecules, where $N_{L}=2.479 \times 10^{19}$ molecules $/ \mathrm{cm}$ atm is Loschmidt's number and $T_{a}$ is the temperature in K. $P_{a}$ is the partial pressure of the molecule of interest in atm. The number density of the molecules of interest is $N P_{a}$, whereas the total number density of molecules is $N P_{T}$, where $P_{T}$ is the atmospheric pressure in atm. The concentration of molecules of interest is thus

$$
c=\frac{N P_{a}}{N P_{T}}=\frac{P_{a}}{P_{T}} .
$$

Using Beer's law, which relates the transmission as a function of the optical depth by $T=e^{-\alpha L}$, and the above two equations, the concentration for the molecular species of interest is $^{26}$

$$
c=\frac{-\ln (T)}{S g\left(v-v_{0}\right) N_{L}\left(\frac{296}{T_{a}}\right) P_{T} L} .
$$

Values for the linestrength, $S$, and normalized lineshape, $g\left(v-v_{0}\right)$, are tabulated in the highresolution transmission molecular absorption (HITRAN) database. ${ }^{42}$ With measurements of the transmission for a known pathlength, temperature, and pressure, a retrieval of the molecular concentration can be completed using Eq. (3).

The subsurface concentration of $\mathrm{CO}_{2}$ can range up to $10,000 \mathrm{ppm}$ depending on soil moisture, temperature, and microbial activity. A plot of the transmission as a function of wavelength is shown in Fig. 1 for a pathlength of $L=1 \mathrm{~m}$ with a total atmospheric pressure of $P_{T}=1 \mathrm{~atm}$ and an ambient temperature of $T_{a}=288 \mathrm{~K}$. The solid black line (dashed blue line and dotted red line) represents the transmission spectrum for a $2000 \mathrm{ppm}\left(10,000 \mathrm{ppm}\right.$ and 60,000 ppm) $\mathrm{CO}_{2}$

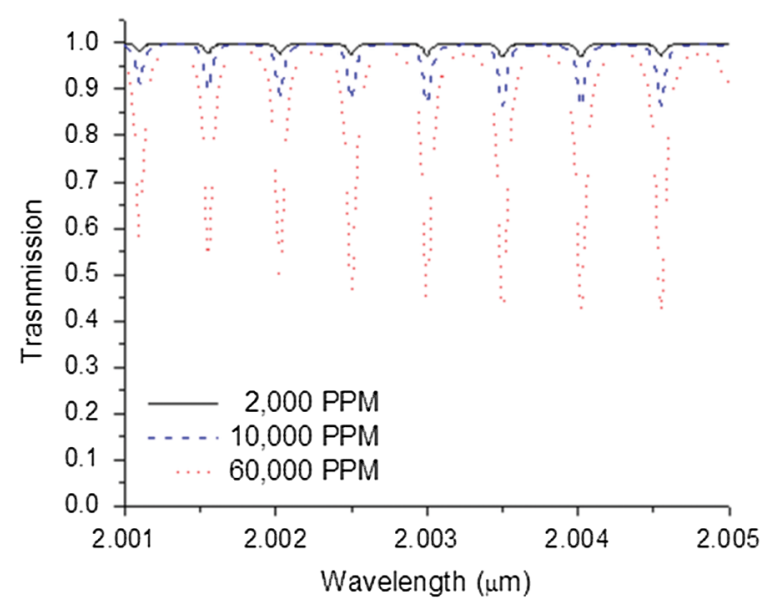

Fig. 1 Transmission as a function of wavelength for a 1-m pathlength, a temperature of $288 \mathrm{~K}$, and a pressure of $1 \mathrm{~atm}$. The black solid line (blue dashed line and red dotted line) represents calculations based on a $\mathrm{CO}_{2}$ concentration of $2000 \mathrm{ppm}(10,000 \mathrm{ppm}$ and $60,000 \mathrm{ppm})$. This range of $\mathrm{CO}_{2}$ concentration represents the expected subsurface $\mathrm{CO}_{2}$ concentration that will be seen at a geologic sequestration site with background levels typically between 2000 and 8000 ppm depending on microbial activity and meteorological conditions. 
Table 1 The wavelength, linestrength, and normalized lineshape for the eight strongest $\mathrm{CO}_{2}$ absorption features in the 2.001- to 2.005- $\mu \mathrm{m}$ wavelength range. The two absorption lines used in the experiment described in this article are highlighted.

\begin{tabular}{lcc}
\hline \hline Wavelength $(\mu \mathrm{m})$ & Line strength $10^{-21}($ molecules $/ \mathrm{cm})$ & Normalized lineshape $(\mathrm{cm})$ \\
\hline 2.0011020 & 0.8112 & 1.1600 \\
2.0015577 & 0.9316 & 1.1516 \\
2.0020255 & 1.048 & 1.1401 \\
2.0025057 & 1.153 & 1.1304 \\
2.0029980 & 1.241 & 1.1161 \\
2.0035036 & 1.302 & 1.1022 \\
2.0040192 & 1.332 & 1.0842 \\
2.0045482 & 1.332 & 1.0653 \\
\hline \hline
\end{tabular}

concentration. These values of $\mathrm{CO}_{2}$ concentration were chosen as the representative of the range of subsurface $\mathrm{CO}_{2}$ concentrations expected at a geologic sequestration site. The maximum expected absorption for the line centered at $2.00402 \mu \mathrm{m}$ for a $\mathrm{CO}_{2}$ concentration of $2000 \mathrm{ppm}(10,000 \mathrm{ppm}$ and $60,000 \mathrm{ppm})$ is $2.9 \%$ (13.6\% and $57.8 \%)$. The transmission measured by the instrument and the resulting calculated $\mathrm{CO}_{2}$ concentrations will be based around the 2.00402- $\mu \mathrm{m}$ absorption line. Values for the wavelength, linestrength, and lineshape for the eight strongest $\mathrm{CO}_{2}$ absorption features in 2.001- to $2.005-\mu \mathrm{m}$ wavelength range are presented in Table 1.

\section{Instrument Description}

A schematic of the fiber sensor array is shown in Fig. 2. A DFB laser operating at $2.004-\mu \mathrm{m}$ is mounted in a 14 pin butterfly package with a fiber-pigtailed output. The DFB laser has an internal thermoelectric cooler (TEC) that allows temperature tuning of the DFB laser. The DFB laser is mounted in a commercial mount that provides a second TEC that is used to stabilize the ambient temperature in which the DFB laser operates. This second TEC is important during field operations, where temperatures can range between a low of $0^{\circ} \mathrm{C}$ at night to a high of $35^{\circ} \mathrm{C}$ during the day. The fiber-coupled output from the DFB laser is nonisolated and directly incident on an inline fiber splitter, which uses multimode optical fiber, with $50 \%$ of the light from one port directed to a reference detector. The remaining $50 \%$ of the light from the second port is

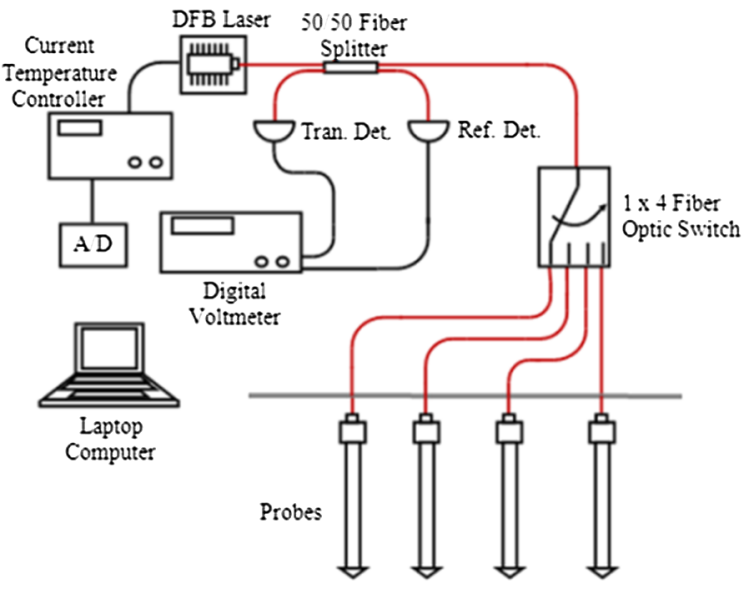

Fig. 2 Schematic of the $1 \times 4$ fiber sensor array. 
directed to an inline $1 \times 4$ fiber optic switch. The inline opto-mechanical fiber optic switch has an insertion loss of less than $0.6 \mathrm{~dB}$ with a crosstalk of less than $-60 \mathrm{~dB}$. Each of the four fibercoupled output ports is connected via a multimode fiber optic cable to a probe that is placed into the ground. These probes collimate the light and allow it to interact with the $\mathrm{CO}_{2}$ that diffuses into the buried probes through Millipore filters placed at the top and bottom of the probes. These filters allow the soil gas to diffuse into the probes but keep out dirt and water. The light is then recoupled into the multimode optical fiber, where it is directed back through the fiber optic switch, and is again incident on the inline fiber splitter, where light from one port is directed to a transmission detector. The reference and transmission detectors are monitored using a multichannel voltmeter that can be read by a computer via a GPIB interface.

The laser temperature and current are regulated using a Wavelength Electronics dual laser driver and TEC controller (WTC0520). This unit has the option for both onboard and remote control capability. The laser current is run at a constant $50 \mathrm{~mA}$ using an onboard trimpot. The laser temperature is controlled remotely by the computer for tuning over the desired range. This operation requires a digital to analog converter (DAC) to convert the digital program commands to analog voltage signals for input into the temperature controller. The actual temperature of the laser is monitored in real time with feedback from the built-in laser thermistor, but is not used as feedback to control the laser temperature. Before field deployment, the laser wavelength was calibrated to specific temperatures. Based on this calibration, the temperature is scanned through a range of temperatures containing the absorption features of interest. In this way, actual TEC temperature, and thus the laser wavelength, can be monitored and controlled from a single panel in the Labview control program.

During field deployment, very little change in wavelength was observed in the laser operation. Minor shifts were expected to occur in the laser output wavelength due to age or extreme environmental temperature changes, but these effects were minimally observed. Any slight change in the temperature-wavelength correlation of the laser was mitigated by the programming, which always seeks out the minima of the returned intensity and assigns it to the proper absorption feature. Long-term study of the laser change in wavelength due to use would be useful for further understanding of system performance.

A schematic of the fiber probes is shown in Fig. 3. The optical fiber from the $1 \times 4$ fiber optic switch is a multimode optical fiber with a core diameter of $62.5 \mu \mathrm{m}$ (Optequip A20134) with angled physical contact (FC/APC) connector. This connector couples to the fiber probe via a keyed FC/APC connector mounted in the top-end cap of the probe. The light exiting the fiber is collimated with an aspheric, fiber-coupled collimator which has a focal length of $f=11 \mathrm{~mm}$ and a reflectivity of $<3 \%$. The collimated light travels to the mirror mounted in a commercial optical mount that reflects the light back through the collimating lens and back into the optical fiber. The mirror mount has a resistive heater attached to ensure that the condensation does not form on the mirror when the fiber probe is buried for extended periods of time. A thermistor is also placed in the fiber optic probe to allow temperature measurements needed for the data inversion discussed in Sec. 2. Millipore filters in both the top-end cap and bottom-end cap allow soil gas to move into and out of the fiber probe when the fiber is buried, while keeping out dirt and water. The overall length of the fiber probe is $60 \mathrm{~cm}$ with a $50-\mathrm{cm}$ free space pathlength where the light and $\mathrm{CO}_{2}$ interact. The diameter of the end caps are $5.0 \mathrm{~cm}$, while the diameter of the narrower central tube is $3.8 \mathrm{~cm}$. The fiber probes are made out of aluminum. A picture of the four completed probes is shown in Fig. 3. During field deployment, each of the four probes was buried in large diameter PVC tube that had been perforated with 3/16 in. holes to allow for soil gas to pass through the tube unimpeded. This was done to allow for easy access to the probes once buried. In the event the return signal was lost and the probes could easily be removed from the ground for inspection and maintenance. However, during field testing, the probes did not require removal once placed in the ground. Originally, the probes were also designed with piezzo-electric transducers mounted behind the mirror to help peak up the return signal after an undesired strain or stress on the probe caused some loss in return intensity. Once it was realized that the fiber probes remained at peak signal for long durations of time, the piezzos were removed from the system.

The instrument is operated using software developed in the Labview programming environment. Data are collected in the following manner. Once the channel to the desired probe is set, the 


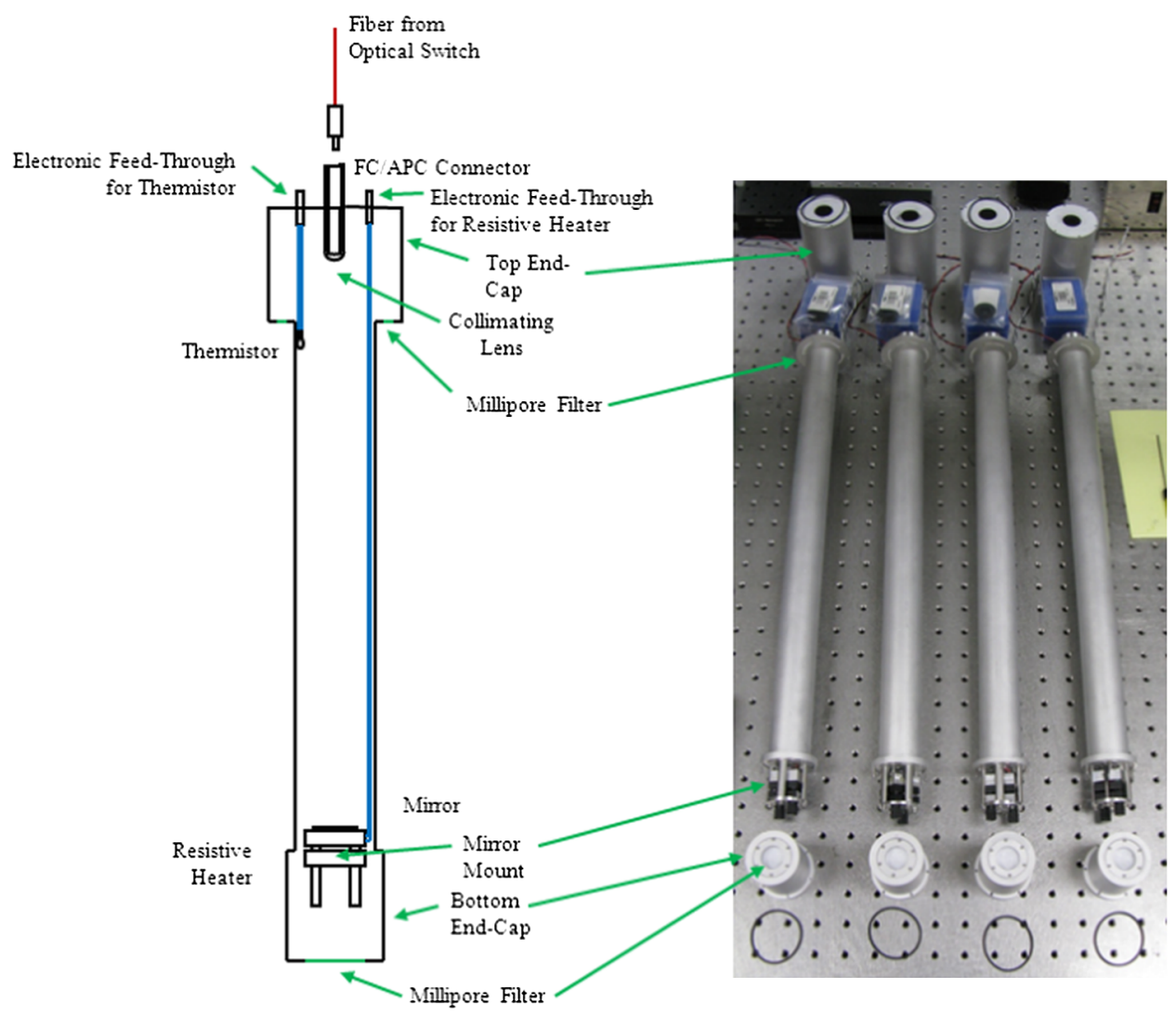

(a)

(b)

Fig. 3 Schematic of the fiber probe is shown in (a) and four completed fiber probes are shown in (b).

programming begins a digital ramp to slowly tune the laser by stepping its operating temperature. This is a basic positive ramp function that outputs a voltage to a DAC, in which the user can set the step size and start/stop values of the function. At each step of the voltage ramp, the DAC converts the value to its analog counterpart and outputs it to the laser TEC controller. This, in turn, causes a small positive change in temperature for the diode and thus a small increase in wavelength. During each step of the temperature, the computer records a reference signal value (voltage) from the laser, a transmission signal from the probe, and the subsurface temperature. The reference and transmission signals are actually recorded several times per step, and the median value is recorded for that temperature (wavelength) step. This is done to help mitigate any noise or modulation while the laser stabilizes to that temperature. The dwell time at each step, the step size, and the time between each reference and transmission measurements are all defined by the user. Experimental measurements show that the laser requires at least $1 \mathrm{~s}$ to settle into each temperature and to stabilize the output wavelength. During the actual field testing of the instrument, each temperature step took about $4 \mathrm{~s}$, allowing ample time for the laser wavelength to stabilize and the computer to monitor accurately the reference and transmission signals.

A single scan for a probe takes about $7 \mathrm{~min}$, contains 100 points of measurement for the reference/transmission signals (mean values), and moves the laser through a temperature range from 33 to $39^{\circ} \mathrm{C}$. Once a scan is completed, the transmission is normalized and the molecular concentration can be back calculated using the results in Sec. 2, and the program moves on to the next probe to repeat the entire process.

\section{Controlled Subsurface Release Experiment}

The ZERT field site ${ }^{35,36}$ is a controlled $\mathrm{CO}_{2}$ release facility located on the western edge of Montana State University in Bozeman, Montana $\left(45^{\circ} 39^{\prime} \mathrm{N}, 111^{\circ} 04^{\prime} \mathrm{W}\right)$, at an elevation of 
$1495 \mathrm{~m}$. The ZERT site has a buried horizontal release pipe that was developed to simulate a longitudinal $\mathrm{CO}_{2}$ leak source, such as a geologic fault or a weakness in a geologic capstone atop a subsurface reservoir, for the development and testing of near-surface and surface monitoring tools for carbon sequestration. A picture of the ZERT field site is shown in Fig. 4 along with a picture of the fiber array instrument deployed at the sight. The site is on a relatively flat alluvial plain that consists of thick sandy gravel deposits overtopped by several meters of silts, clays, and topsoil. The buried release pipe is $98-\mathrm{m}$ long with an inner diameter of $10.16 \mathrm{~cm}$ and is oriented $45 \mathrm{deg}$ east of true north. The central $70 \mathrm{~m}$ of the pipe is perforated to seep $\mathrm{CO}_{2}$ during injection. A series of eight packers was placed within the release pipe to assist in dispersing the gas evenly along the slotted portions of the release pipe with each of the eight sections of pipe plumbed with its own flow controller. The pipe was buried using a horizontal drilling technique that minimized disturbance to the surface environment; however, the pipe installation was deflected from a perfectly straight path because of cobble in the gravel-layer underground.

A 34-day release experiment was performed beginning from July 10, 2012. The $\mathrm{CO}_{2}$ release rate for this experiment was 0.15 tons $\mathrm{CO}_{2} /$ day, about the equivalent to two idling cars, evenly distributed over the eight sections of the underground pipe. The flow rate was chosen in the following manner. Approximately $4 \times 10^{6}$ tones $\mathrm{CO}_{2} /$ year can be captured from a $500 \mathrm{MW}$ fossil fuel-burning power plant. Over a 50-year period, this would result in a total of $200 \times 10^{6}$ tones $\mathrm{CO}_{2}$ which could be sequestered. Assuming that the injection area is approximately $1 \%$ of a typical geologic fault in size, the flow rate was chosen so that the seepage would mimic less that $0.01 \%$ through a typical fault. This implies that the flow rate chosen mimics the levels that need to be monitored and observed at geologic sequestration sites.

A plot of the normalized transmission as a function of wavelength is shown in Fig. 5. The solid red line represents the normalized transmission measured using one of the four probes during the release experiment. The Labview program used to collect and process the data, which was described in Sec. 3 above, returned a $\mathrm{CO}_{2}$ concentration of 50,926 ppm. The dashed blue line in Fig. 5 is a plot of the transmission as a function of wavelength based on this $\mathrm{CO}_{2}$ concentration resulting from the HITRAN database. Good agreement between the measured and expected results indicates that the fiber sensor probe and corresponding software are working properly.

The fiber sensor instrument was operated for a 58-day period, providing subsurface $\mathrm{CO}_{2}$ concentration measurements from each of the four probes. A plot of the $\mathrm{CO}_{2}$ concentration as a function of time for each of the four probes between July 5 and July 9, 2012, periods is shown in Fig. 6. This data were collected before the subsurface $\mathrm{CO}_{2}$ began providing background data. During this 4-day period, the $\mathrm{CO}_{2}$ concentration ranged between 1000 and 7000 ppm. A diurnal cycle is evident in Fig. 6 with a maximum $\mathrm{CO}_{2}$ concentration occurring around 1:00 pm local time. There is a general decline in measured $\mathrm{CO}_{2}$ concentrations after this time leading to a general minimum about $12 \mathrm{~h}$ later. This diurnal cycle is related to the subsurface microbial activity as well as the surface meteorological conditions and soil moisture. Secondary peaks do occur at a couple of points in the last 2 days shown in Fig. 6, which most likely correspond to the changes in wind speed or air pressure due to inclement weather. These changes in

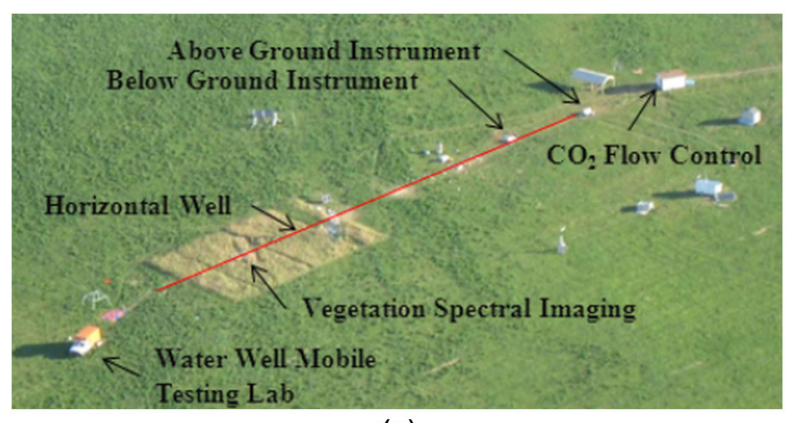

(a)

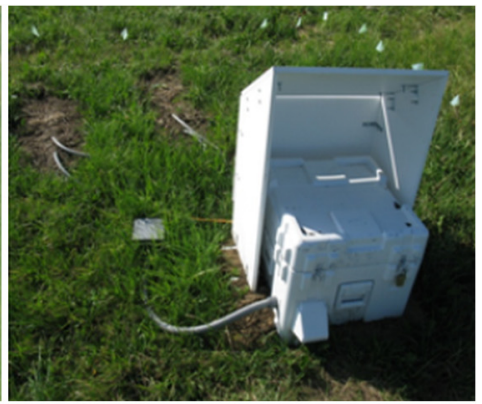

(b)

Fig. 4 The Zero Emission Research Technology (ZERT) field site is shown in (a) with the subsurface pipe location and below ground fiber instrument locations marked. The fiber sensor probe deployed at the ZERT site is shown in (b). 


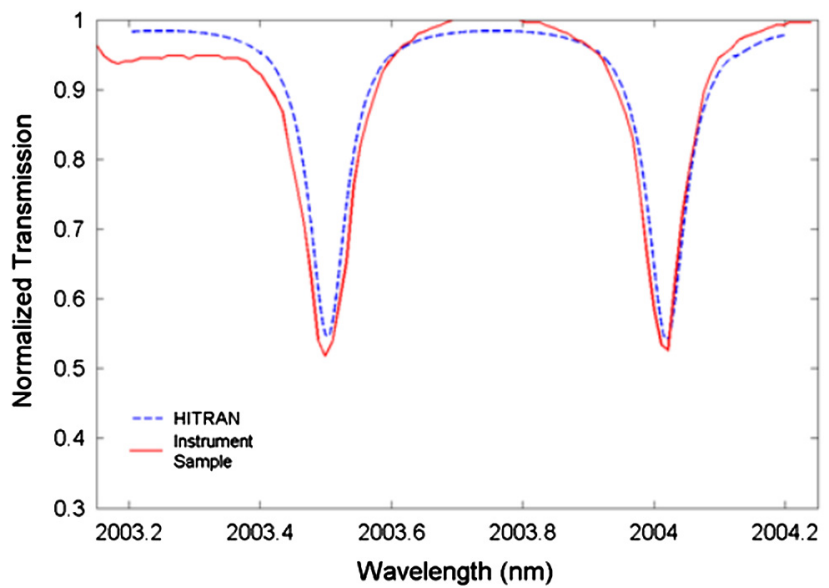

Fig. 5 A plot of the normalized transmission as a function of wavelength. The solid red line represents the normalized transmission measured using one of the four probes during the release experiment. The calculated $\mathrm{CO}_{2}$ concentration from this measured transmission was $50,926 \mathrm{ppm}$. The dashed blue line is a plot of the transmission as a function of wavelength based on this $\mathrm{CO}_{2}$ concentration resulting from the high-resolution transmission molecular absorption (HITRAN) database.

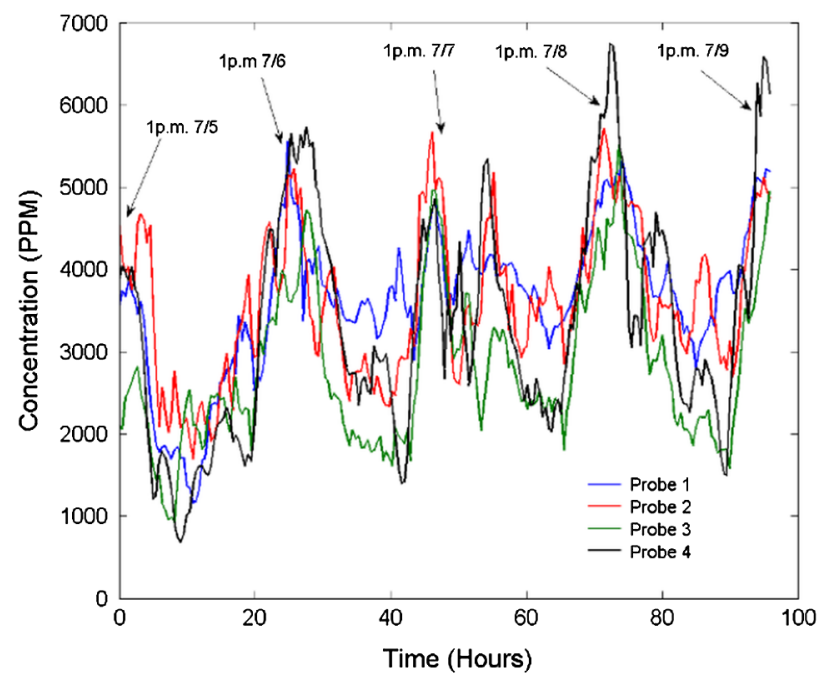

Fig. 6 A plot of the $\mathrm{CO}_{2}$ concentration as a function of time for each of the four probes measured over a 4-day period before the beginning from July 5, 2012, at X:XX pm local time. These data were collected before the beginning of the controlled subsurface $\mathrm{CO}_{2}$ release and providing background measurements. A diurnal cycle of subsurface $\mathrm{CO}_{2}$ concentration is seen by each of the four probes with $\mathrm{CO}_{2}$ concentrations ranging between 1000 and $7000 \mathrm{ppm}$. The diurnal cycle is most likely due to microbial activity and meteorological conditions.

surface condition can drastically effect how $\mathrm{CO}_{2}$ rises from the dirt. This data show that each of the four fiber probes is able to monitor background $\mathrm{CO}_{2}$ concentration levels.

A plot of the $\mathrm{CO}_{2}$ concentration as a function of time for each of the four probes over a 58day period is shown in Fig. 7. The four probes were located roughly on the corners of a rectangle with an area of about $1 \mathrm{~m}^{2}$. The front two probes were placed closest to the pipe at a $0.5-\mathrm{m}$ perpendicular distance with a maximum depth of about $1 \mathrm{~m}$. The remaining two were shifted back by about another $0.5 \mathrm{~m}$. All four probes were buried at 45-deg angles with respect to the horizontal surface. The $\mathrm{CO}_{2}$ release began at 12:00 pm local time on July 10, 2012, and lasted until August 13, 2012, with the release start time and stop marked in Fig. 7 with vertical lines. Data were collected 22 days before the start of the release to ensure that the instrument was able to monitor background levels. During this first 21 days, the background $\mathrm{CO}_{2}$ concentrations 


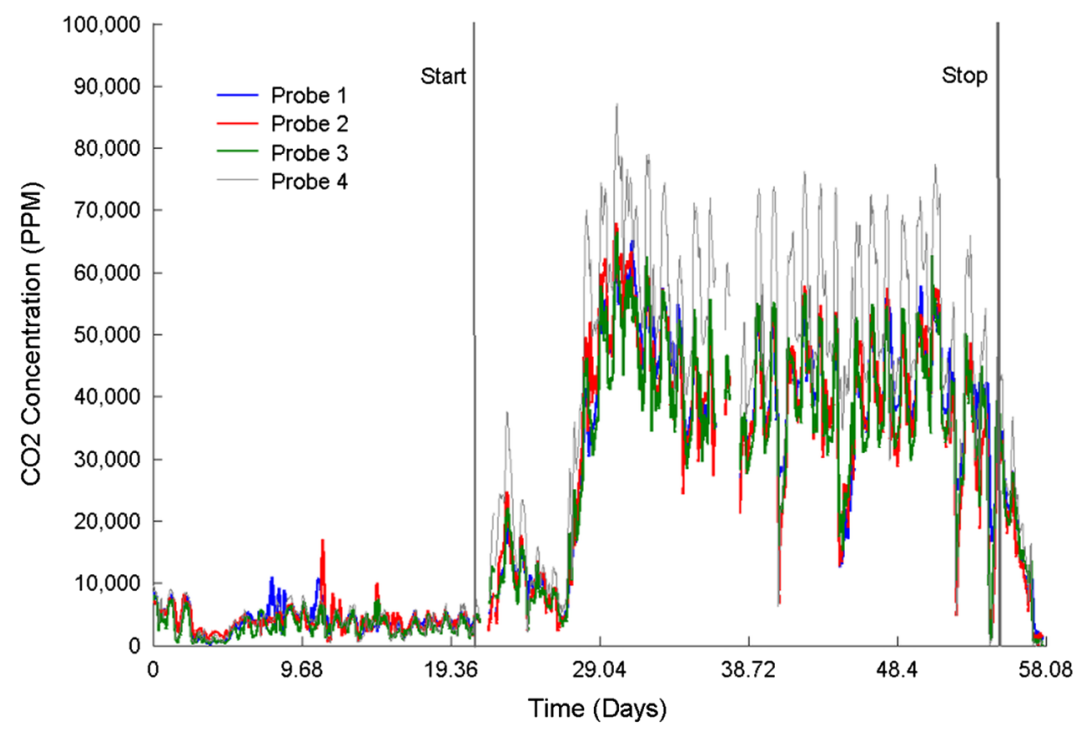

Fig. 7 A plot of the subsurface $\mathrm{CO}_{2}$ concentration as a function of time for each of the four probes over a 58-day period. The start and stop of the controlled subsurface $\mathrm{CO}_{2}$ release are indicated by the solid vertical lines. A rise in the subsurface $\mathrm{CO}_{2}$ concentration by over a factor of 6 over background levels indicates that the fiber sensor array can detect changes in subsurface $\mathrm{CO}_{2}$ concentration at the level needed for geologic carbon sequestration.

fluctuated between 1000 and 7000 ppm showing a daily diurnal cycle. After the start of the release, the subsurface $\mathrm{CO}_{2}$ concentration began to rise in each of the four probes after approximately 1 day. This delay in the measured rise in subsurface $\mathrm{CO}_{2}$ concentration results from the time it takes for the $\mathrm{CO}_{2}$ to move from the release pipe to the location of the fiber sensor probes. About 2 days into the release experiment, a lightning strike caused a power outage and damaged the flow controllers, causing the $\mathrm{CO}_{2}$ flow to be stopped. This is clearly seen in the data in the drop in $\mathrm{CO}_{2}$ concentration until about 6 days after the start of the release at which time the $\mathrm{CO}_{2}$ flow started again, and each of the four probes measured a rapidly rising $\mathrm{CO}_{2}$ concentration which reached peak levels of about $65,000 \mathrm{ppm}$, for three of the four probes, until the release was stopped. The other probe registered values greater than 70,000 ppm during the release. Once the release was stopped, it took approximately 3 days for the subsurface $\mathrm{CO}_{2}$ concentration values to fall back to their steady-state background levels.

\section{Conclusions}

A fiber optic sensor array for subsurface $\mathrm{CO}_{2}$ concentration measurements has been demonstrated at the ZERT-controlled subsurface release facility over a 58-day period. This $1 \times 4$ fiber sensor array utilizing a send/call configuration uses a single-tunable DFB laser and fiber optic components to make subsurface $\mathrm{CO}_{2}$ concentration measurements based on IPDA techniques. This instrument was successfully deployed over a 58-day period, measuring background $\mathrm{CO}_{2}$ concentrations over 21 days, measuring the changing subsurface $\mathrm{CO}_{2}$ concentrations in each of the four probes resulting from a 31-day subsurface controlled release, and finally monitoring the relaxation back to background levels for the 3 days after the injection was stopped. Background $\mathrm{CO}_{2}$ concentrations ranged between 1000 and $7000 \mathrm{ppm}$, while the release was designed to mimic the conditions needed for successful geologic sequestration site monitoring with concentrations ranging over $70,000 \mathrm{ppm}$.

The $1 \times 4$ fiber optic sensor array can be scaled in a cost-effective manner for monitoring larger areas. Inline fiber optic switches based on the same technology used by the $1 \times 4$ switch employed in this demonstration instrument are available in a number of geometries with up to 50 output ports. The part count for the expensive components including the DFB laser, detectors, and fiber optic switch does not increase as the number of probes increases, and the probes have been designed to be made inexpensively. This allows the fiber sensor array to be scaled 
inexpensively with the added benefit that the fiber probes can be placed as needed and easily moved, providing for a reconfigurable sensor.

The fiber sensor array is currently used for the subsurface $\mathrm{CO}_{2}$ detection. The ability to monitor other subsurface gases including methane $\left(\mathrm{CH}_{4}\right)$ and oxygen $\left(\mathrm{O}_{2}\right)$ can provide process-based information that can help determine the origin of the $\mathrm{CO}_{2} \cdot{ }^{43}$ For example, if photosynthesis is occurring, then the ratio of the change in $\mathrm{CO}_{2}$ will be related to the ratio of the change in $\mathrm{O}_{2}$. The ability to monitor other soil gasses with a similar geometry can be incorporated through adding tunable DFB lasers at the appropriate wavelengths and using wavelength division multiplexers to allow for spectroscopy of multiple species in a single probe. Future research efforts are aimed at achieving this goal.

\section{Acknowledgments}

This work is supported by the National Energy Technology Laboratory and the Department of Energy Project number DE-FE0001858. However, any opinions, findings, conclusions, or recommendations expressed herein are those of the author's and do not necessarily reflect the views of the DOE.

\section{References}

1. Scripps $\mathrm{CO}_{2}$ Program (Scripps), Monthly Average Carbon Dioxide Concentration, Scripps Institute of Oceanography, http://scrippsco2.ucsd.edu/graphics_gallery/mauna_loa_record/ mauna_loa_record.html (November 2012).

2. P. Tans and R. Keeling, "Trends in atmospheric carbon dioxide," NOAA/ESRL \& Scripps Institute of Oceanography, http://www.esrl.noaa.gov/gmd/ccgg/trends/ (January 2012).

3. K. Masarie and P. P. Tans, "Extension and integration of atmosphere carbon dioxide data into a globally consistent measurement record," J. Geophys. Res. 100(D6), 11593-11610 (1995), http://dx.doi.org/10.1029/95JD00859.

4. P. P. Tans, "How can global warming be traced to $\mathrm{CO}_{2}$ ?," Sci. Am. 295(6), 124 (2006).

5. M. Scheffer, V. Brovkin, and P. M. Cox, "Positive feedback between global warming and atmospheric $\mathrm{CO}_{2}$ concentration inferred from past climate change," Geophys. Res. Lett. 33(10), L10702 (2006), http://dx.doi.org/10.1029/2005GL025044.

6. M. R. Raupach et al., "Global and regional drivers of accelerating $\mathrm{CO}_{2}$ emission," Proc. Natl. Acad. Sci. U. S. A. 104(24), 10288-10293 (2007), http://dx.doi.org/10.1073/pnas.0700609104.

7. IPCC, M. L. Parry et al., Eds., Climate Change 2007: Impacts, Adaptation and Vulnerability. Contributions of Working Group II to the Fourth Assessment Report of the Intergovernmental Panel on Climate Change, pp. 976, Cambridge University Press, Cambridge, UK (2007).

8. T. R. Karl, J. M. Melillo, and T. C. Peterson, Eds., Global Climate Change Impacts on the United States, Cambridge University Press, Cambridge, UK (2009).

9. J. Alcamo and G. J. J. Kreileman, "Emission scenarios and global climate protection," Global Environ. Change 6(4), 305-334 (1996), http://dx.doi.org/10.1016/S0959-3780 (96)00030-1.

10. R. T. Watson, Ed., Climate Change 2001. Synthesis Report. A Contribution of Working Groups I, II, and III to the Third Assessment Report of the Intergovernmental Panel on Climate Change, Cambridge University Press, Cambridge, UK (2001).

11. J. Hansen, "Defusing the global warming time bomb," Sci. Am. 290(3), 68 (2004), http://dx .doi.org/10.1038/scientificamerican0304-68.

12. R. J. Norby and Y. Luo, "Evaluating ecosystem responses to rising atmospheric $\mathrm{CO}_{2}$ and global warming in a multi-factor world," New Phytol. 162(2), 281-293 (2004), http://dx.doi .org/10.1111/nph.2004.162.issue-2.

13. K. W. Thoning, , P. P. Tans, and W. D. Komhyr, "Atmospheric carbon dioxide at Mauna Loa Observatory 2. Analysis of the NOAA GMCC data, 1974-1985," J. Geophys. Research. 94(D6), 8549-8565 (1989).

14. K. Y. Vinnikov and N. C. Grody, "Global warming trend of mean tropospheric temperature observed by satellites," Science 302(5643), 269-272 (2003), http://dx.doi.org/10.1126/ science. 1087910 . 
15. R. A. Houghton, "Balancing the global carbon budget," Annu. Rev. Earth Plant. Sci. 35, 313-347 (2007), http://dx.doi.org/10.1146/annurev.earth.35.031306.140057.

16. B. Metz et al., Ed., Climate Change 2001-Mitigation. The Third Assessment Report of the Intergovernmental Panel on Climate Change, Cambridge University Press, Cambridge, UK (2001).

17. H. J. Herzog, "What future for carbon capture and sequestration?," Environ. Sci. Tech. 35(7), 148-153 (2001).

18. B. Metz et al., Ed., Intergovernmental Panel on Climate Change Special Report on Carbon Dioxide Capture and Storage, Cambridge University Press, Cambridge, UK (2005).

19. Lawrence Berkeley National Laboratory, "An overview of geologic sequestration of $\mathrm{CO}_{2}$," in ENERGEX'2000: Proc. 8th Int. Energy Forum, Las Vegas, Nevada (2000).

20. T. $\mathrm{Xu}$, " $\mathrm{CO}_{2}$ geological sequestration," Encyclopedic Knowledge Chinese Encyclopedic Press, Vol. 304, Paper LBNL-56644-JArt (November 2004).

21. Z. Li et al., " $\mathrm{CO}_{2}$ sequestration in depleted oil and gas reservoirs-caprock characterization and storage capacity," Energy Conserv. Manage. 47(11-12), 1372-1382 (2006), http://dx .doi.org/10.1016/j.enconman.2005.08.023.

22. T. A. Torp and J. Gale, "Demonstrating storage of $\mathrm{CO}_{2}$ in geologic reservoirs: the Sleipner and SACS projects," Energy 29(9-10), 1361-1369 (2004), http://dx.doi.org/10.1016/j .energy.2004.03.104.

23. S. G. Whittaker et al., "Characterizing the geologic container at the Weyburn Field for subsurface $\mathrm{CO}_{2}$ storage associated with enhanced oil recovery," in Proc. Diamond Jubilee Convention of the Canadian Society of Petroleum Geologists, Calgary, Canada (2002).

24. S. G. Whittaker, "Investigating geological storage of greenhouse gases in southeastern Saskatchewan: The IEA Weyburn $\mathrm{CO}_{2}$ Monitoring and Storage Project," Saskatchewan Geological Survey, Sask. Industry Resources, Summary of Investigations, Vol. 1 (2004).

25. J. T. Lityski et al., "The United States Department of Energy's regional carbon sequestration partnerships validation phase," Environ. Int. 34(1), 127-138 (2008), http://dx.doi.org/10 .1016/j.envint.2007.07.005.

26. K. S. Repasky, S. Humphries, and J. L. Carlsten, "Differential absorption measurements of carbon dioxide using a temperature tunable distributed feedback diode laser," Rev. Sci. Instrum. 77(11), 113107 (2006), http://dx.doi.org/10.1063/1.2370746.

27. S. M. Benson et al., "Monitoring protocols and life-cycle costs for geologic storage of carbon dioxide," in Proc. 7th Int. Conf. on Greenhouse Gas Control Technologies (GHGT-7), E. S.Rubin, D. W. Keith, and C. F. Gilboy, Eds., pp. 1259-1266, IEA Greenhouse Gas Programme, Vancouver, BC (2004).

28. E. J. Wilson, S. J. Friedmann, and M. F. Pollak, "Research and development: incorporating risk, regulation, and liability for carbon capture and sequestration," Environ. Sci. Technol. 41, 5945-5952 (2007), http://dx.doi.org/10.1021/es062272t.

29. J. L. Barr et al., "Laser based carbon dioxide monitoring instrument testing during a thirty day controlled underground carbon release field experiment," Int. J. Greenhouse Gas Control 5(1), 138-145 (2011), http://dx.doi.org/10.1016/j.ijggc.2010.03.002.

30. J. L. Lewicki et al., "Surface $\mathrm{CO}_{2}$ leakage during the first shallow subsurface $\mathrm{CO}_{2}$ release experiment," Geophys. Res. Lett. 34, L24402 (2007), http://dx.doi.org/10.1029/ 2007 GL032047.

31. J. L. Lewicki et al., "Eddy covariance observations of surface leakage during shallow subsurface $\mathrm{CO}_{2}$ releases," J. Geophys. Res. Atmos. 114(D12) (2009).

32. D. D. Baldocchi, "Assessing the eddy covariance technique for evaluating carbon dioxide exchange rates of ecosystems: past, present, and future," Global Change Biol. 9(4), 479-492 (2003), http://dx.doi.org/10.1046/j.1365-2486.2003.00629.x.

33. D. P. Billesbach et al., "A portable eddy covariance system for measurement of ecosystematmosphere exchange of $\mathrm{CO}_{2}$, water vapor, and energy," J. Atmos. Ocean. Technol. 21(4), 639-650 (2004), http://dx.doi.org/10.1175/1520-0426(2004)021<0639:APECSF>2.0 .CO;2.

34. V. Weldon, P. Phelan, and J. Hegarty, "Methane and carbon dioxide sensing using a DFB laser diode operating at $1.64 \mu \mathrm{m}$," Electron. Lett. 29(6), 560-561 (1993), http://dx.doi.org/ 10.1049/el:19930374. 
Soukup et al.: Field demonstration of a $1 \times 4$ fiber sensor array for subsurface carbon dioxide...

35. R. Yu et al., "Real-time carbon dioxide emission monitoring system based on participatory sensing," in Fourth International Workshop on Advanced Computational Intelligence, Wuhan, Hubei, China (19-21 October 2011).

36. R. Phelan et al., "Investigation of a strongly gain coupled DFB laser cascade for simultaneous multigas sensing," IEEE Proc. 150(2), 182-186 (2003), http://dx.doi.org/10.1049/ipopt:20030314.

37. A. A. Kosterev et al., "Portable spectroscopic carbon dioxide monitor for carbon sequestration applications," in Lasers and Electro-optics, 2009, and Conference on Quantum Electronics and Laser Science, CLEO/QELS, Baltimore, MD (2009).

38. A. Ksendzov et al., "Linewidth measurement of high power diode laser at $2 \mu \mathrm{m}$ for carbon dioxide detection," Electron. Lett. 48(9), 520-522 (2012), http://dx.doi.org/10.1049/el.2012 .0363 .

39. Agiltron, Lightbend $1 \times \mathrm{N}$ Broadband Fiber Optic Switch, http://agiltron.com/pdfs/lb\% 201xn\%20broad\%20bend.pdf (December 2013).

40. S. D. Humphries et al., "Testing carbon sequestration site monitoring instruments using a controlled carbon dioxide release facility," Appl. Opt. 47(4), 548-555 (2008), http://dx.doi .org/10.1364/AO.47.000548.

41. L. H. Spangler et al., "A controlled field pilot in Bozeman, Montana, USA, for testing near surface $\mathrm{CO}_{2}$ detection techniques and transport models," Environ. Earth Sci. 60, 227-239 (2010), http://dx.doi.org/10.1007/s12665-009-0400-2.

42. L. S. Rothman et al., "The HITRAN molecular spectroscopic database," J. Quant. Spectrosc. Radiat. Transfer 82, 5-44 (2003), http://dx.doi.org/10.1016/S0022-4073(03) 00146-8.

43. K. D. Romanak et al., "Process-based approach to $\mathrm{CO}_{2}$ leakage detection by vadose zone gas monitoring at geologic $\mathrm{CO}_{2}$ storage sites," Geophys. Res. Lett. 39(15), L15405 (2012), http://dx.doi.org/10.1029/2012GL052426.

Benjamin Soukup earned a BS degree in physics from Montana State University in 2011, and he is currently working on his MS in electrical engineering. His research is focused on the development and testing of optical remote sensing instruments for carbon dioxide detection. This includes instruments utilizing both the IPDA technique and range resolved measurements using a DIAL.

Kevin S. Repasky received a BE in mechanical engineering from Youngstown State University 1987, and his MS and PhD in physics from Montana State University in 1992 and 1996. He is currently an associate professor in the Electrical and Computer Engineering Department at Montana State University and has recently been appointed a visiting scientist at the National Center for Atmospheric Research. His research interests include laser and photonic development, nonlinear optics, optical remote sensing, and atmospheric science.

John L. Carlsten holds a BS degree in physics from the University of Minnesota (1969) and MS and PhD degrees in physics from Harvard University (1974). Currently, he holds the position of regents professor of physics at Montana State University. Previously he has held positions at the University of Colorado (1974 to 1979) and the Los Alamos National Laboratory (1979 to 1984). Currently he is collaborating with Prof. Kevin Repasky of the Electrical and Computer Engineering Department on lidar applications to water vapor DIAL, aerosol measurements, and carbon dioxide monitoring. He is a fellow in the American Physical Society and is a fellow in the Optical Society of America.

Geoffrey Wicks is a physics graduate student at Montana State University, and is currently performing research in the field of femtosecond molecular spectroscopy, specifically making high-accuracy measurements of the two-photon absorption (2PA) cross section spectra of chromophore molecules. He is interested in direct measurements of intramolecular charge transfer and analysis of its behavior in different molecular environments, and 2PA measurements of molecular series with systematically varied structural and electronic properties provide access to this delicate information. In his spare time he enjoys camping, biking, and destroying electronics with his two sons. 